\title{
An Experimental Study and Mathematical Modeling of Vibration Transfer in Pistachio Trees Using an Inertia-Type Trunk Shaker and Field-Adapted Wireless Sensors
}

\author{
Ruijun Ma $\mathbb{D}^{1,2}$ Taymaz Homayouni $\mathbb{D}^{1},{ }^{2}$ Arash Toudeshki $\mathbb{D}^{2}$, Reza Ehsani $^{1},{ }^{2}$ \\ and Xiaohua Zhang ${ }^{3}$ \\ ${ }^{1}$ College of Engineering, South China Agriculture University, 483 Wushan Road, Guangzhou 510642, China \\ ${ }^{2}$ Mechanical Engineering Department, School of Engineering, University of California Merced, 5200 N. Lake Rd., Merced, \\ CA 95343, USA \\ ${ }^{3}$ College of Automation, Zhongkai University of Agriculture and Engineering, 501 Zhongkai Road, Guangzhou 510225, China
}

Correspondence should be addressed to Ruijun Ma; maruijun_mrj@scau.edu.cn and Reza Ehsani; rehsani@ucmerced.edu

Received 31 March 2021; Revised 23 December 2021; Accepted 29 January 2022; Published 27 February 2022

Academic Editor: Salvatore Caddemi

Copyright (C) 2022 Ruijun Ma et al. This is an open access article distributed under the Creative Commons Attribution License, which permits unrestricted use, distribution, and reproduction in any medium, provided the original work is properly cited.

Trunk shakers are the most widely used mechanical harvesting machines for harvesting nut trees, including pistachio in California. Improvement of these machines requires a better understanding of the shaking dynamics of the existing trunk shakers during harvest. In this study, the effects of four different shaking patterns on three sizes of pistachio trees of different ages, shapes, and sizes were investigated under field conditions. The vibration acceleration of the real pistachio tree was measured using a wireless network of 3-axis accelerometers installed on the shaker head and different parts of the trees during the shaking harvest. Changes in acceleration and the effect of tree morphology on the magnitude of acceleration in each pattern are presented and discussed. A new location index $\lambda$, which is based on the distance of the sensor from the shaking point and diameter of the branch at each sensor location, is introduced. This study focused on mathematical modeling of the variation and distribution of the acceleration throughout the tree canopy. The sensor location index, relative force ratio (RFR), and relative kinetic energy ratio (RKER) were defined to better understand the energy damping in each part of the tree. The results showed that the relationship between the acceleration peaks and the sensor location index could be expressed by a third-degree polynomial function with an acceptable coefficient of determination. Under different shaking patterns, similar changes in the RFR of the tree at different locations and for different trees were observed. This finding indicates that the vibration force is significantly damped as the distance from the shaker clamps increases. However, the RKER values at the same shaking pattern result in different effects at different points on the branches according to tree morphology.

\section{Introduction}

Pistachio production has rapidly expanded in the state of California, and the majority of the acreage is located in the San Joaquin Valley, where over $90 \%$ of the U.S., pistachio crop is located [1]. In 2019, California pistachio acreage was $393,595(288,595+105,000$, bearing plus unbearing) acres [2]. Mechanical trunk shaker harvesting machines are the primary method of harvesting pistachios in California. Since the 1920s, shake-based harvesting machines have been used in the U.S. fruit and nut crops $[3,4]$, and trunk shakers have been used since the early 1960s $[5,6]$. Although trunk shakers are widely used for harvesting nut trees in California, there is not a sufficient amount of published scientific study about the efficiency of these machines. Therefore, a comprehensive study is required to determine the characteristics of the shaking method that these shakers presently use. The methods proposed in this study will provide design engineers with more information about the performance of these harvesting machines under field conditions. Using this information, they could potentially make modifications to improve the shaking mechanism or shaking pattern to 
achieve higher fruit removal during harvest. The improved shaking performance also has the potential to reduce branch breakage and bark and tree damage, which often result in decreased production in subsequent years $[7,8]$. In addition, improving shaking performance will increase the energy efficiency of a mechanical trunk shaker, resulting in lower operating costs.

The most significant factor influencing fruit removal during mechanical harvesting is tree structure [9]. Láng [10] built a dynamic modeling structure of a fruit tree and presented a model of a tree-shaker system based on using an inertial shaker system. Hoshyarmanesh et al. [11] built a 3D model for an average-sized tree. Moreover, they simulated and studied the effects of shaking frequency, loading type, and loading height on olive-stem-twig joint rupture. Gupta et al. [12] presented a methodology to analytically model and optimize different limb prototypes for citrus tree shakers.

The acceleration produced at the point between the peduncle and the calix (abscission zone) is one of the important factors influencing fruit removal efficiency. Therefore, Liu et al. [13] measured the density of the green citrus wood and investigated the minimum force needed to remove a fruit at different pulling angles; they also analyzed the acceleration and detachment force at the fruit joint. It is also important to know how the kinetic energy transmits to fruiting branches and causes a force that is greater than the required detachment force on the fruit-stem interface to detach the fruit from the tree. In this regard, Affeldt et al. [6] measured acceleration with accelerometers and extracted displacements using the linear variable differential transformers technique in the $x$ and $y$-directions for cherry tree trunk shakers. Later, Abdel-Fattah et al. [14] collected acceleration data on a commercial shaker and reported a linear relationship between the displacement on the shaker arm and the displacement on the wooden post. Amirante et al. [15] measured acceleration along the $x$-axis and $y$-axis on the shaker and trunk of an olive tree and displayed the spectrogram of the acceleration for the $x$-axis of the shaker and the trunk. They also presented the variation pattern of the acceleration vector in the $x-y$ plane during the vibration test. Catania et al. [16] measured the acceleration and evaluated the vibrations transmitted to the hand-arm system while using a portable harvester for olive trees. Castro-Garcia et al. [17] measured acceleration using a triaxial accelerometer inserted inside fruits and analyzed the vibration of the fruit during the fruit detachment process for a canopy shaker for oranges.

Castro-Garcia et al. [18] found a significant linear relationship between the tree trunk acceleration and vibration frequency for trunk shaker harvesting of table olives. There was also a significant relationship between the trunk acceleration and shaker head acceleration. Moreover, they have reported that the shaker clamp can affect acceleration transmission from the trunk shaker to the tree trunk depending on its geometry, the characteristics of its rubber pads, and its grabbing pressure. In another study, AbdelFattah et al. [14] stated that the resulting vibration transmission from the machine to the tree can be determined by a combination of machine design and the characteristics of the tree itself. Liu et al. [19] compared different types of tree shaking tines in a mechanical citrus canopy shaker by an experimental study of the vibrational acceleration spread from the machine to the fruit. The effect of shaking at different parts of the citrus tree was also investigated by using analog accelerometers [20].

He et al. [21] showed that when using the shaking method, fruit location has a critical influence on apple fruit detachment. Their test results revealed that the amount of acceleration that is transmitted to the fruit was the key factor for fruit detachment during mechanical harvesting. As was expected, fruit that received lower excitation energy during shaking was not detached. It was also found out that the location of fruit within the canopy plays a critical role in the efficiency of the acceleration transmission.

He et al. [22] also investigated the energy efficiency of a mechanical harvesting shaker used for cherry harvesting. They determined that the kinetic energy delivered to an exciting branch, on average, accounted for $60 \%, 77 \%, 92 \%$, and $95 \%$ when the input excitation energy was at the respective shaking frequencies of $6,10,14$, and $18 \mathrm{~Hz}$. Higher shaking frequency resulted in higher total energy delivered to all monitored branches and a higher percentage of input energy distributed to excite the desired branches. In order to quantitatively analyze the capability of the kinetic energy being converted along the tree branches, Du et al. [23] set up a sweet cherry tree specimen in the laboratory and defined the relative kinetic energy ratio (RKER).

Knowing more information about the effects of vibration on the tree and fruit could help in the selection of the bestoperating conditions and contribute towards enhancing mechanical harvesting machines [24]. Few studies have been conducted on the acceleration response of trees under field conditions, especially for pistachio trees during harvest using a trunk shaker. This study focuses on the monitoring 3D acceleration of pistachio trees and how it varies and transmits from the tree trunk to a branch while the tree is shaken using a commercial pistachio trunk shaker. The objectives of this study were to evaluate the sensor location index $(\lambda)$, relative force ratio (RFR), and RKER to find the relationship between acceleration and the sensor location index and to analyze the trend of RFR and RKER transferred from the trunk to a tree branch for four different trunk shaking patterns.

\section{Materials and Methods}

2.1. Inertia-Type Trunk Shaker. Field experiments were conducted at a pistachio orchard at Kern County, which is located in the southwest part of the San Joaquin Valley, California. The data were collected in the second week of October 2018. The C7 R-SERIES MK2 catching frame shaker (Coe Orchard Equipment, Inc., Live Oak, CA, USA), an inertia-type trunk shaker mechanical harvesting machine (Figure 1), was used in this experiment. The harvesting machine was equipped with a computerized shaking pattern controller that allowed the operator to define different shaking patterns by controlling and changing the magnitude of shaking frequency and the duration of shaking. 


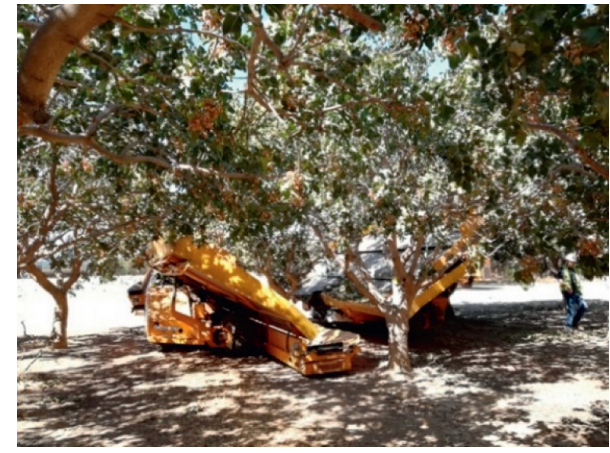

FIgURE 1: The inertia-type trunk shaker mechanical harvesting machine used in this experiment on a pistachio tree.

The shaker head was firmly clamped to the trunk at a height of $0.3 \mathrm{~m}$ from the ground level, and the whole tree was shaken. Four different shaking patterns (P1, P2, P3, and P4) were used in this experiment (Figures 2(a)-2(d)). In these figures, the $x$-axis is a shaking time in seconds, and the $y$-axis is the per-unit magnitude of the hydraulic flow rate which is produced by the shaker machine during each experiment. The pattern P2 (Figure 2(b)) is similar to pattern P1 (Figure 2(a)); their only difference was in the maximum magnitude at $1 \mathrm{~s}$ of shaking time. In P1, the hydraulic oil flow rate increased from 0.5 unit at $0 \mathrm{~s}$ to 0.8 at $1 \mathrm{~s}$ and reduced to 0.45 unit and 0 at $2 \mathrm{~s}$, while in $\mathrm{P} 2$, the hydraulic flow increased from 0.5 unit at $0 \mathrm{~s}$ to 0.6 at $1 \mathrm{~s}$ and reduced to 0.45 unit and 0 at $2 \mathrm{~s}$. This difference of magnitude of the hydraulic flow rate at $1 \mathrm{~s}$ between P1 and P2 was applied on a limited number of trees used for this experiment because the machine operators claimed that producing the hydraulic flow rate with a magnitude of more than 0.6 unit can significantly damage the bark of the tree's trunk of the large trees and break the branches. In P3 (Figure 2(c)), the magnitude is kept constant at 0.5 unit for one second and then gradually decreases to 0 . Finally, in P4, two-step functions (consecutive vibration patterns of 0.5 unit for 1,0 flow rate for $0.7 \mathrm{~s}$, and 0.6 unit for $0.8 \mathrm{~s}$ ) are executed, as shown in Figure 2(d). The time of the rising edge and falling edge of the step function is both approximately equal to $28 \mathrm{~ms}$. The duration of shaking of each shaking pattern was less than $3 \mathrm{~s}$. A 5-minute delay gap was applied between each generated shaking pattern. The reason for applying this delay between each shake was to make sure the tree completely terminated undesirable oscillation before applying the new shaking pattern. Since the purpose of this experiment was to study the vibration transfer in pistachio trees, the shakes were applied after harvesting the fruits to avoid any sudden mass change due to the detachment of fruits. Therefore, the experimental conditions remained persistent for all different shaping patterns, and the result was not affected by the past shaking pattern.

2.2. Sensor and Data Logger System. A vibration generated by a shaker head on the trunk can be transferred and distributed across different parts of the tree, including branches, leaves, and fruits. The amount of vibration can be measured in the form of acceleration. Measuring the acceleration assists in calculating other significant factors that are caused by this vibration, including force, velocity, displacement, and energy. Microelectromechanical accelerometer sensors can measure acceleration in realtime. Using commercially available accelerometers was not suitable for this project because the majority of them were not able to tolerate the harsh environment present in the field. The data generated by these accelerometers must be recorded in a data logger with a high sampling rate and a large storage memory. Moreover, the system should be able to collect data wirelessly. Using long cables to deliver the electric power from the power supply to the accelerometer and transferring the measured data from the accelerometer to the data logger would not have been feasible to install and use for this project. Therefore, a new wireless sensor and data logger was designed and built for this experiment.

The in-house designed wireless sensor included a 3-axis MEMS accelerometer (LIS3DH) and an IEEE 802.11n support $2.4 \mathrm{GHz} \mathrm{WiFi}$ (ESP8266EX), which were powered by a $9 \mathrm{~V}$ battery. A dustproof and tree branch mountable enclosure was designed and $3 \mathrm{D}$ printed to protect the wireless sensor and its battery using a polylactic acid material. The remote data logger for this system was Raspberry Pi 3 B+ with a 16 G.B. micro-SD card running Raspbian Stretch Lite (minimal image based on Debian 9 Stretch) operating system, which was supplied with a $12 \mathrm{~V}$ sealed lead acid generator battery with a capacity of $10 \mathrm{Ah}$. The wireless sensor was able to communicate with the data logger through a wireless local area network designed for in-field applications. Moreover, a database was designed for recording data sent from unlimited numbers for wireless sensors. A user-friendly interface was designed for in-field filtering, monitoring, and downloading data.

2.3. Experimental Setup. A set of wireless accelerometers was fixed at different locations throughout the primary, secondary, and tertiary branches of each tree to acquire acceleration responses to input excitations. The vibratory excitations generated from the shaker head of the shaker were applied perpendicularly to the trunk. As shown in Figure 3, three adjacent pistachio trees with different sizes and shapes were chosen for experiments. The criteria for tree selection were mainly based on the trunk diameters and total lengths from the ground to the fruit location in the installed sensor paths. At the time of this experiment, the age of selected trees were 27, 17, and 13 years old. These trees were almost representing large, medium, and small sizes trees planted in different years in this orchard. The trunk circumferences of these selected trees were 96.2, 41.5, and $28.3 \mathrm{~cm}$. The trunk diameter of the trees shown in Figures 4(a) and 4(b) was 1.8 and 1.2 times more than the tree in Figure 4(c). In addition, the total length of the sensor installed path from the ground to the fruit location of the trees shown in Figures 4(a) and 4(b) was 1.7 and 1.3 times more than this length in the tree, which is shown in Figure 4(c). 


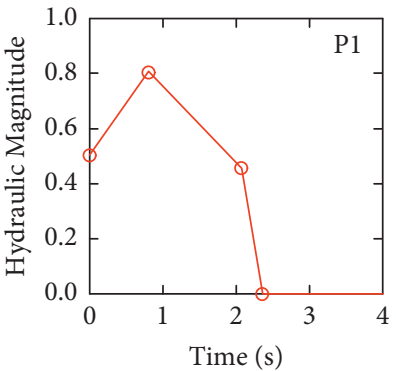

(a)

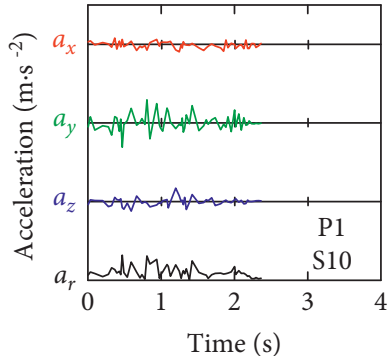

(e)

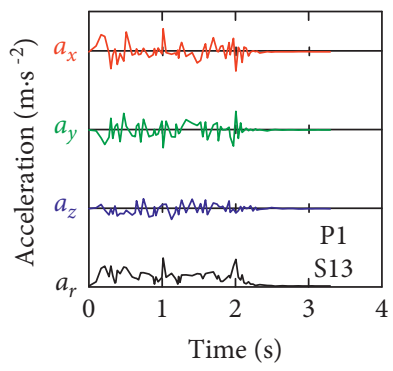

(i)

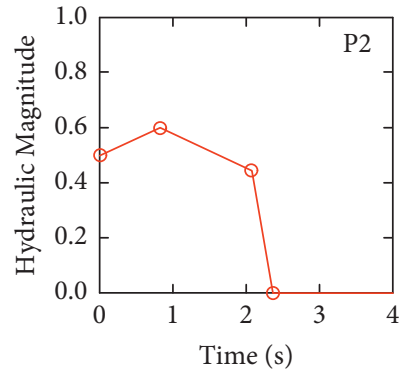

(b)

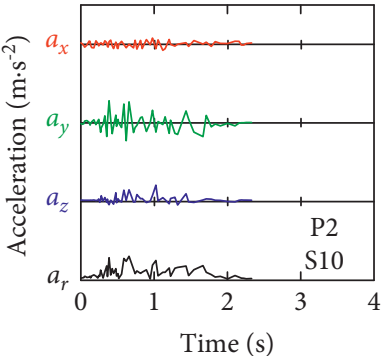

(f)

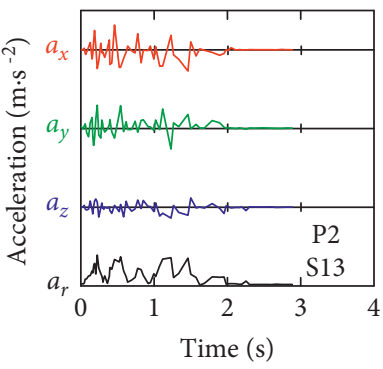

(j)

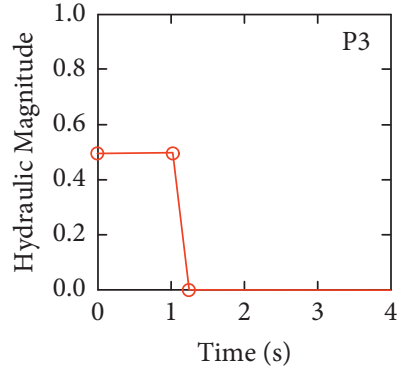

(c)

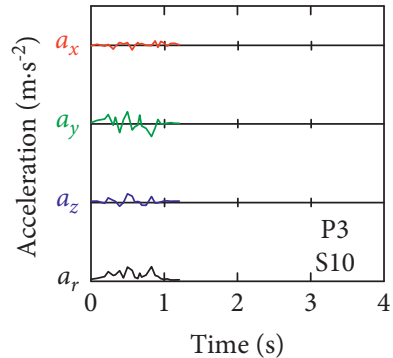

(g)

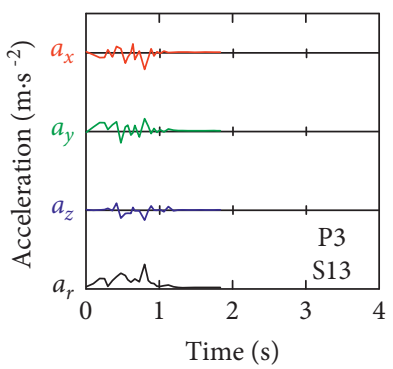

(k)

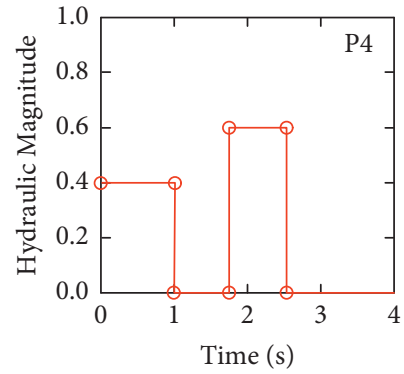

(d)

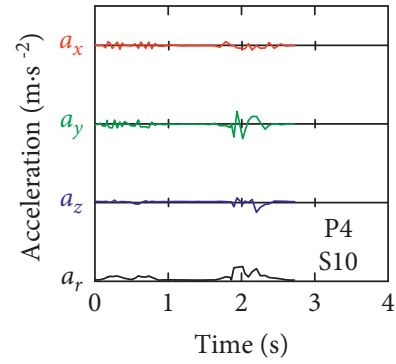

(h)

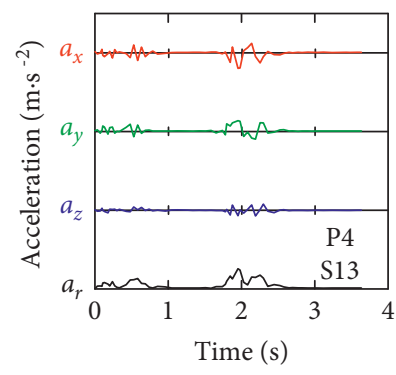

(1)

FIGURE 2: Shaking patterns (a) P1, (b) P2, (c) P3, and (d) P4; generated acceleration in three axes on location S10 installed on the shaker by the shaking pattern (e) P1, (f) P2, (g) P3, and (h) P4; and the received acceleration in three axes at the location of S13 installed on the third branch of tree I by the shaking pattern (i) P1, (j) P2, (k) P3, and (l) P4.

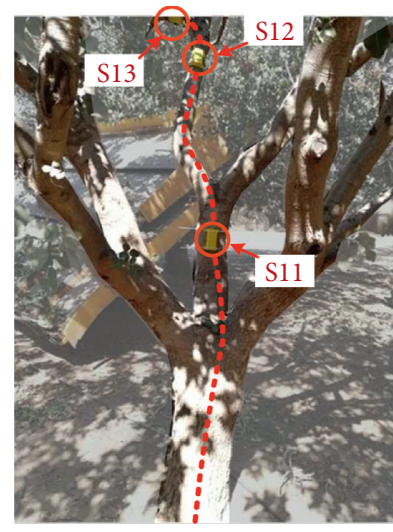

(a)

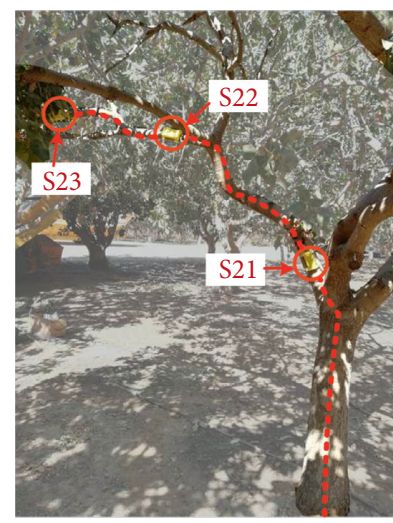

(b)

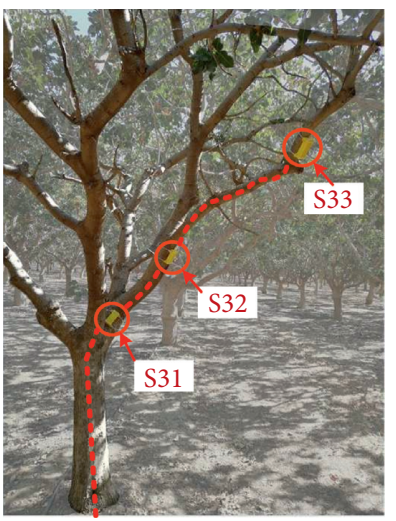

(c)

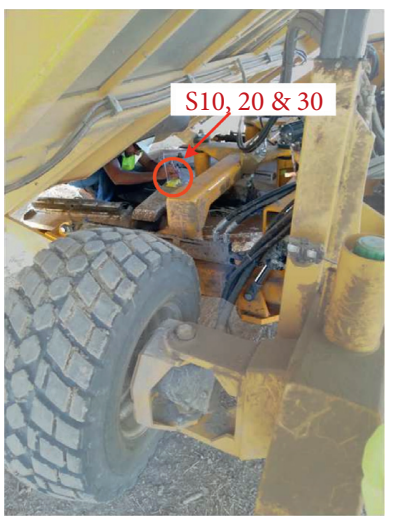

(d)

Figure 3: Accelerometers were installed on (a) tree I, (b) tree II, (c) tree III, and (d) the shaking axle of the shaker.

A total of ten wireless accelerometers were used in these experiments; one was installed on the shaker head, which was labeled as S10 for the first tree, S20 for the second tree, and S30 for the third tree in Figure 4. The other nine sensors were installed on the three trees, positioned on the first branch, middle branch, and top branch of the tree; the 


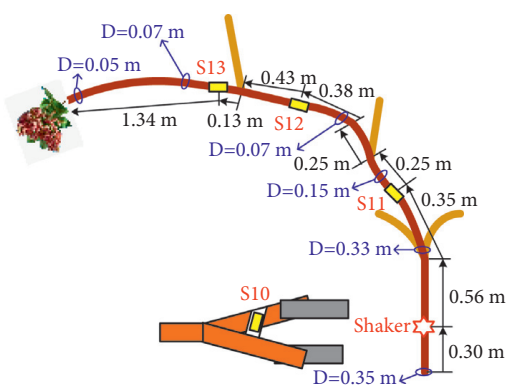

(a)

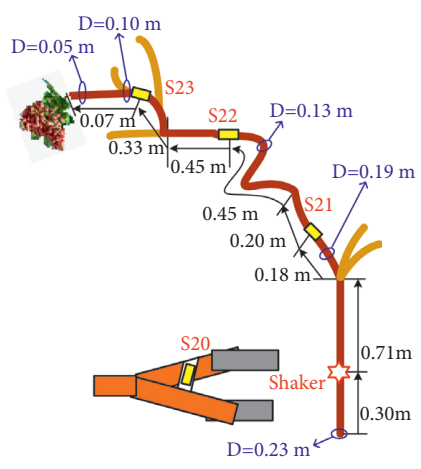

(b)

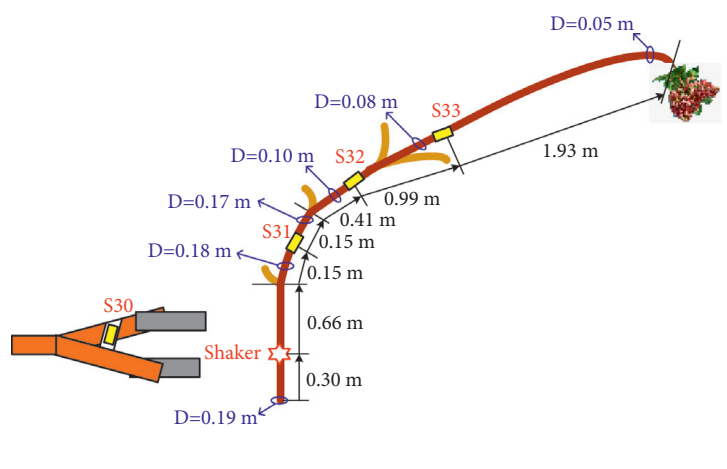

(c)

FiguRE 4: The location of sensors (yellow boxes) on the shaker head (orange color) and first, second, and third branches (brown color) of (a) tree I, (b) tree II, and (c) tree III.

locations were named $S_{t b}$, where $t$ is the tree number (from 1 to 3 ) and $b$ is the branch number (from 1 to 3 ) on which the accelerometer was installed.

Any vibration can be detected and measured by these accelerometers and immediately transferred to the remote data server through the in-field local wireless network. The sensor was set at a range of $\pm 16 \mathrm{G}$ and sensitivity of $\pm 1 \mathrm{G}$. The total mass of the wireless accelerometer sensor, battery, and housing weighed $98 \mathrm{~g}$. The orthogonal axes of a LIS3DH accelerometer are shown in Figure 5(a). The orientation of the accelerometer installed on the shaker head of the machine is shown in Figure 5(b), and the placement of the accelerometer on the branch of the tree is shown in Figure 5(c). In all sensor installations, $a_{x}$ and $a_{y}$ are parallel with the surface of the $x-y$ plane of the vibrated object, and $a_{z}$ is perpendicular to this plane.

Due to practical limitations, it is assumed that the acceleration of the trunk at the clamped point is the same as the acceleration on the shaker head. In this case, the directions of measured acceleration on the trunk are similar to those shown in Figure 5(b). The frequency weighted root mean square acceleration was evaluated for each axis, and the acceleration resultant $a_{r}$, in $\mathrm{m} \cdot \mathrm{s}^{-2}$, was obtained by the following equation $[7,19]$ :

$$
\left|a_{r}\right|=\sqrt{a_{x}^{2}+a_{y}^{2}+a_{z}^{2}} .
$$

2.4. Sensor Location Index. The sensor location index was used for the first time by $\mathrm{He}$ et al. [21]. In this study, the sensor location index $(\lambda)$ for each sensor is defined by equation (2). This index represents the sum of the ratio of length to diameter from the shaking point at the trunk of the tree to the location of the sensor installed.

$$
\lambda_{n}=\sum_{i=1}^{n} \frac{L_{i}}{D_{i}},
$$

where $n$ is the number of the sensor at the current location, $L_{i}$ in meter $(m)$ is the distance of the sensor from the last sensor point $(i-1)$, and $D_{i}$ in $m$ is the average diameter of the trunk or branch at the sensor location. The subscript $i$ represents the trunk, first branch, second branch, and so on.
It is important to highlight that unlike He et al. [21], we did not use $D / L$ equation because $D$ is never equal to the zero for the trunk and branch of the tree, but $L$ can be equal to zero. Therefore, based on equation (2), in this study, $\lambda$ increases as with distance from the shaking clamped point. Furthermore, to calculate $\lambda$ and avoid complexity, only the ratio of the point-to-point measured distances and diameter of the point that the sensor was installed was used, and this was assumed that the angle of branches does not affect this index.

2.5. Force and Vibration Transmission. To derive the relative force ratio (RFR), it is assumed that the density $(\rho)$ of the trunk and branch is uniform. By knowing the force $F$ and mass $m$,

$$
\left\{\begin{array}{l}
F_{i}=m_{i} a_{i}, \\
m_{i}=\rho V_{i}, \\
V_{i}=\pi\left(\frac{D_{i}}{2}\right)^{2},
\end{array}\right.
$$

where $V$ is the volume of a unit length trunk or branch and $i$ is the number of the sensor location. Then, the force of a unit length trunk or branch at a location can be calculated by

$$
F_{i}=\frac{1}{4} \pi \rho D_{i}^{2} a_{i}
$$

The RFR is defined to represent force level changes at a specific sensor location $i$ in comparison to a reference point $j$ along the transmission path:

$$
\operatorname{RFR}_{i j}=\frac{F_{i}}{F_{j}}=\frac{D_{i}^{2} a_{i}}{D_{j}^{2} a_{j}} .
$$

By setting the excitation point at the reference position, RFR could be used to calculate the force of any other location relevant to the excitation point.

2.6. Kinetic Energy Transmission and Variation. The relative kinetic energy ration (RKER) that represents energy level 


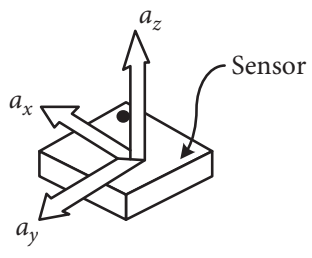

(a)

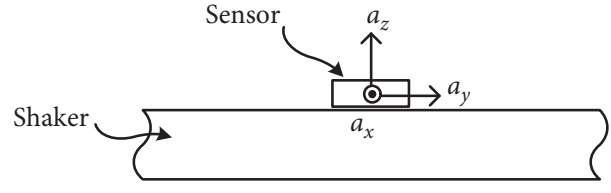

(b)

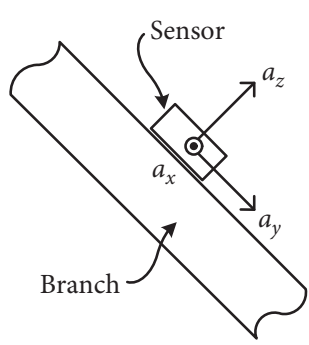

(c)

FIgURE 5: The directions of acceleration (a) on the sensor, (b) machine, (c) and branch.

changes at monitoring location $i$ and $j$ along a transmission path was defined by Du et al. [23] as

$$
\operatorname{RKER}_{i j}=\frac{E_{i}}{E_{j}}=\left(\frac{D_{i} v_{i}}{D_{j} v_{j}}\right)^{2},
$$

where $E$ is the kinetic energy of a unit branch length at the monitored location, $D$ is the diameter of the branch, and $v$ is the velocity, which can be obtained from the integration of the acceleration. Hence, by assuming that the density $\rho$ of the trunk and branch is uniform, $E_{i}$ can be calculated from

$$
E_{i}=\frac{1}{2} m_{i} v_{i}^{2}=\frac{1}{8} \pi \rho D_{i}^{2} v_{i}^{2}
$$

In this study, the maximum velocity response is used to calculate RKER for each shaking pattern by using equation (6).

\section{Results}

3.1. Acceleration throughout the Shaking Process. As an example, the 3 -axis $x, y$, and $z$ components of the accelerations $\left(a_{x}, a_{y}\right.$, and $\left.a_{z}\right)$ and acceleration resultant $\left(a_{r}\right)$ for tree I were measured from the accelerometer S10 and accelerometer S13 and are shown in Figures 2(e)-2(l) under four different excitation patterns (other trees are not shown). Considering the magnitude and time of accelerations, it is clear that the applied shaking patterns shown in Figures $2(\mathrm{a})-2(\mathrm{~d})$ have caused accelerations of Figures 2(e)-2(h) on the shaker head installed sensor S10. In addition, accelerations, shown in Figures 2(i)-2(l), were transmitted to the third branch where the sensor S13 was installed.

\subsection{The Acceleration Trend Changes from the Shaker to the} Branch of the Tree. The magnitude variation of acceleration (three components and resultant) for all sensors installed on three trees (Figure 4) shaken with four different shaking patterns is shown in Figure 6. It was found that the shaking pattern affects the amount of transmission to the last accelerometers installed on the branches with the longest distance from the source of the shake. It also shows that the pattern and magnitude of change are very different for different trees, and values change differently. A similar phenomenon was observed when the experiment was repeated on more trees with different sizes and shapes (Table 1). This may suggest that other parameters such as the angle of the branches or tree morphology could affect the point-to-point transmission of acceleration. Subsequently, as shown in Figure 6, the acceleration magnitude changes from the shaking clamp point to the end of the top branch of the shaken trees. By comparing the magnitude of accelerations in $x, y$, and $z$-directions, in each tree, it is clear that the pattern of acceleration magnitude in Cartesian coordinates transferred to each sensor location in each tree is unpredictable. The cause of this unpredictability can be understood by considering the natural limitation of sensor installation on different trees in an orchard (Figure 3). Natural asymmetric torsions, directions, angle of branches, and overall tree morphology are different from each other in different trees. Therefore, the transmission of acceleration magnitude can significantly be affected by these mentioned morphological causes. However, as shown in Figure 6, the transmission of the resultant acceleration magnitude $\left|a_{r}\right|$ is almost independent of the tree and branches' morphology, and the distribution pattern of this component of the acceleration is almost predictable for most of the trees. In general, the maximum acceleration happened in the first and secondary branches and it is minimum at both ends for most of the cases. Therefore, for the long branch where the fruit is located at the end of the branch, the acceleration is not maximum.

3.3. Models of the Changing Trend of Acceleration. Based on the results of Figure 6, it was observed that tree variety, morphology, and structure are the most significant factors influencing the changes of acceleration, which could potentially affect the fruit removal rate. These differences will give different results for the transmission of acceleration, force, and energy. Nevertheless, the relationship between the peak values of acceleration with $\lambda$ is shown in Figure 7 .

From Figure 7, it can be seen that the relationship between the peak values of acceleration resultant with the sensor location index shows similar results under four different shaking patterns for three different trees. In general, in all trees, the acceleration applied to the trunk decreased for all patterns at $\lambda_{1}$ or at the first branch of the trees. The highest value of acceleration happened between the second and third branches $\left(\lambda_{2}, \lambda_{3}\right)$. However, the average acceleration at the tertiary branches at $\lambda_{3}$ was similar to the acceleration value at $\lambda_{2}$. This suggests a polynomial function can closely estimate the generated resultant acceleration as a 


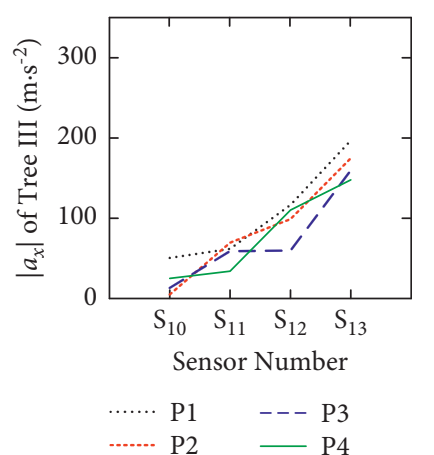

(a)

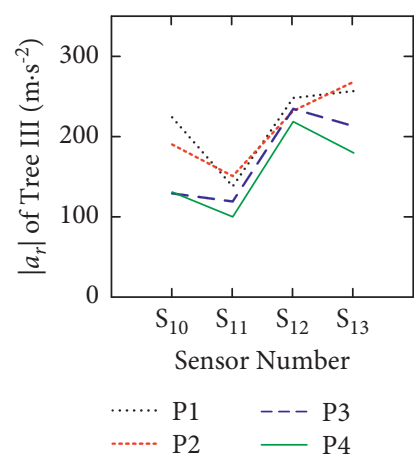

(d)

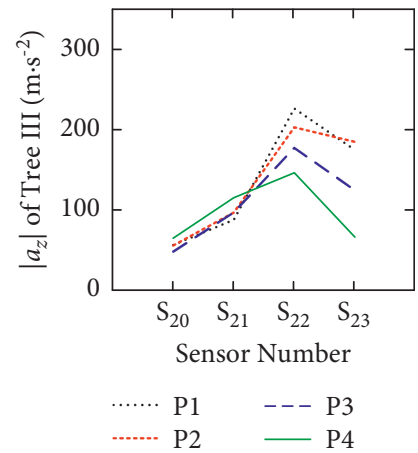

(g)

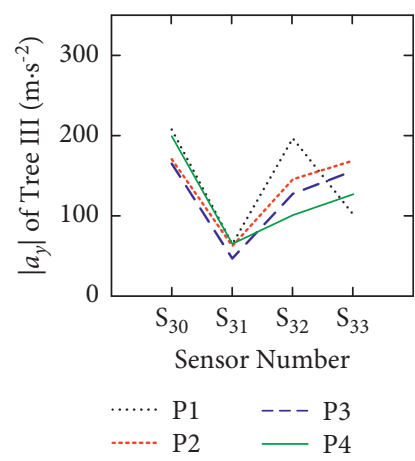

(j)

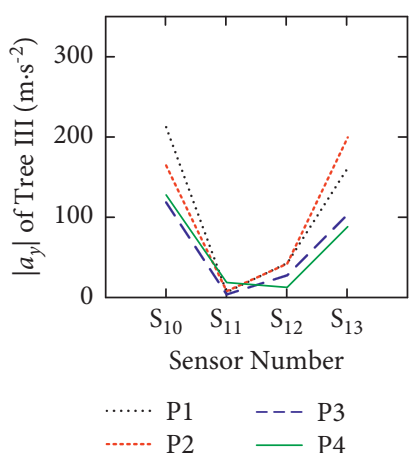

(b)

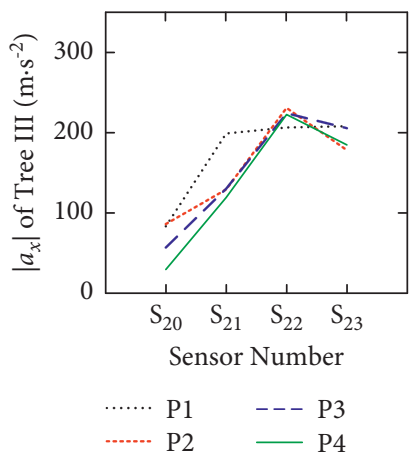

(e)

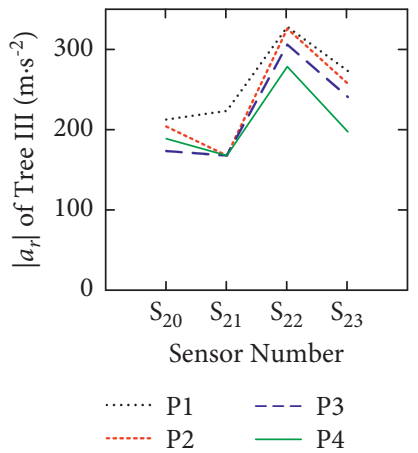

(h)

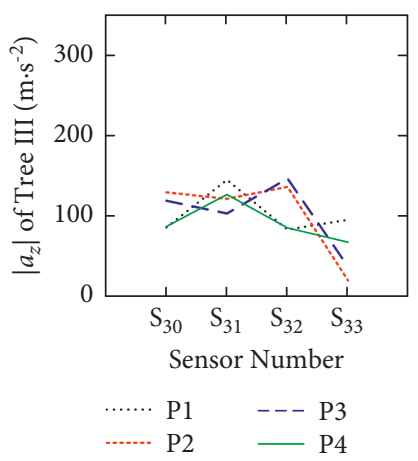

(k)

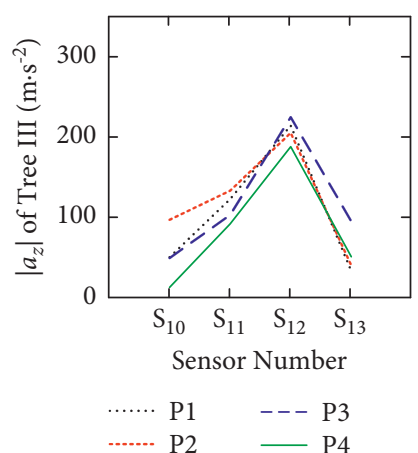

(c)

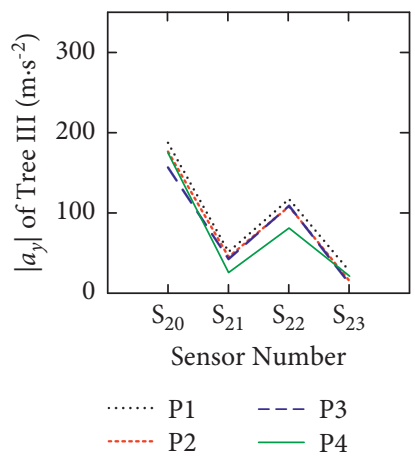

(f)

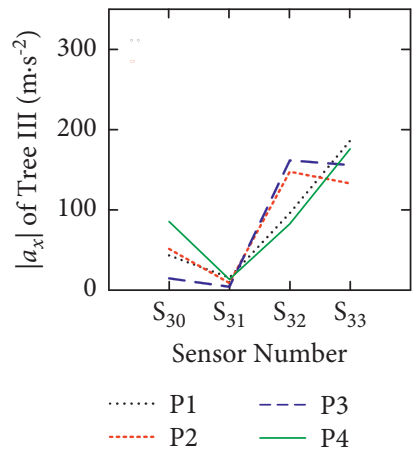

(i)

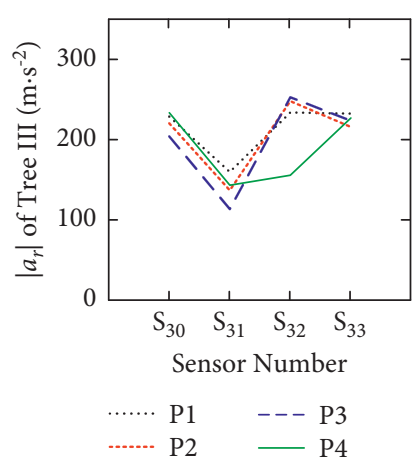

(l)

Figure 6: Acceleration magnitude changes from the shaking clamp point to the end of the top branch of the shaken trees.

function of $\lambda$. If the order of the chosen polynomial function is less than the number of data points minus one, the $\mathrm{R}$-squared value can be less than one. It means that although the model becomes simpler, it cannot fit accurately to all data points. On the other hand, choosing the order of the polynomial model more than the number of data points minus one will cause complexity and increase the unnecessary number of coefficients. Therefore, the optimal order 
TABLE 1: Evaluation of equation (8) for different shaken trees with different patterns (unit for $L$ and $D$ is $\mathrm{m}$ and for a is $\mathrm{m} \cdot \mathrm{s}^{-2}$ ).

\begin{tabular}{lcccccccccccc}
\hline Tree & 1 & 2 & 3 & 4 & 5 & 6 & 7 & 8 & 9 & 10 & 11 \\
\hline Age & 8 & 10 & 11 & 15 & 23 & 23 & 25 & 25 & 27 & 28 & 29 & 29 \\
Pattern & $P 3,4$ & $P 3,4$ & $P 3,4$ & $P 3,4$ & $P 1,2,3,4$ & $P 1,2,3,4$ & $P 2,3,4$ & $P 2,3,4$ & $P 2,3,4$ & $P 2,3,4$ & $P 2,3,4$ & $P 2,3,4$ \\
$L_{1}$ & 1.04 & 0.97 & 1.19 & 1.07 & 1.45 & 1.63 & 1.47 & 1.30 & 1.73 & 1.35 & 0.81 & 1.45 \\
$L_{2}$ & 0.22 & 0.51 & 0.53 & 0.33 & 0.64 & 0.66 & 0.91 & 0.56 & 0.51 & 0.76 & 0.69 & 0.41 \\
$L_{3}$ & 0.53 & 0.46 & 1.09 & 0.46 & 1.30 & 0.46 & 1.22 & 0.91 & 0.61 & 0.76 & 0.84 & 1.07 \\
$D_{0}$ & 0.10 & 0.08 & 0.15 & 0.11 & 0.30 & 0.26 & 0.24 & 0.29 & 0.34 & 0.39 & 0.36 & 0.38 \\
$D_{1}$ & 0.06 & 0.07 & 0.06 & 0.07 & 0.15 & 0.14 & 0.20 & 0.16 & 0.13 & 0.19 & 0.22 & 0.17 \\
$D_{2}$ & 0.04 & 0.05 & 0.05 & 0.06 & 0.08 & 0.08 & 0.09 & 0.11 & 0.12 & 0.12 & 0.14 & 0.11 \\
$D_{3}$ & 0.02 & 0.04 & 0.02 & 0.03 & 0.07 & 0.02 & 0.09 & 0.06 & 0.09 & 0.08 & 0.08 & 0.08 \\
$\lambda_{0}$ & 0.00 & 0.00 & 0.00 & 0.00 & 0.00 & 0.00 & 0.00 & 0.00 & 0.00 & 0.00 & 0.00 & 0.00 \\
$\lambda_{1}$ & 18.40 & 14.04 & 18.46 & 14.66 & 9.68 & 11.49 & 7.29 & 8.01 & 13.35 & 7.24 & 3.72 & 8.53 \\
$\lambda_{2}$ & 23.74 & 23.71 & 29.45 & 20.50 & 17.34 & 20.09 & 17.57 & 12.95 & 17.54 & 13.52 & 8.71 & 12.39 \\
$\lambda_{3}$ & 45.73 & 35.02 & 74.48 & 34.63 & 35.14 & 38.94 & 31.28 & 27.09 & 24.39 & 23.44 & 19.08 & 25.59 \\
$a\left(\lambda_{0}\right)$ & 43.01 & 50.97 & 45.37 & 60.34 & 122.62 & 134.98 & 123.65 & 103.76 & 86.73 & 104.19 & 94.14 & 102.58 \\
$a\left(\lambda_{1}\right)$ & 105.03 & 204.79 & 149.44 & 163.66 & 210.56 & 335.09 & 243.26 & 183.34 & 136.65 & 225.44 & 161.90 & 229.75 \\
$a\left(\lambda_{2}\right)$ & 89.90 & 139.50 & 140.26 & 188.63 & 265.93 & 279.89 & 246.07 & 166.44 & 116.80 & 218.01 & 164.09 & 180.51 \\
$a\left(\lambda_{3}\right)$ & 165.83 & 175.33 & 71.00 & 273.46 & 202.83 & 13.60 & 283.23 & 200.58 & 150.06 & 201.28 & 232.18 & 198.74 \\
$c_{0}$ & 35.805 & 41.470 & 37.145 & 44.610 & 103.168 & 105.315 & 123.650 & 102.073 & 79.990 & 94.340 & 94.140 & 102.580 \\
$c_{1}$ & 23.716 & 32.144 & 5.033 & 5.365 & -0.105 & 24.396 & 27.094 & 13.812 & 23.144 & 24.911 & 32.069 & 48.081 \\
$c_{2}$ & -1.421 & -2.030 & -0.075 & -0.137 & 0.561 & -1.177 & -1.693 & -0.940 & -2.103 & -1.567 & -4.308 & -4.968 \\
$c_{3}$ & 0.021 & 0.034 & 0.000 & 0.003 & -0.014 & 0.018 & 0.031 & 0.020 & 0.052 & 0.030 & 0.156 & 0.126 \\
$R^{2}$ & 0.588 & 0.918 & 0.531 & 0.975 & 0.426 & 0.767 & 0.991 & 0.836 & 0.921 & 0.971 & 0.986 & 0.999 \\
\hline
\end{tabular}

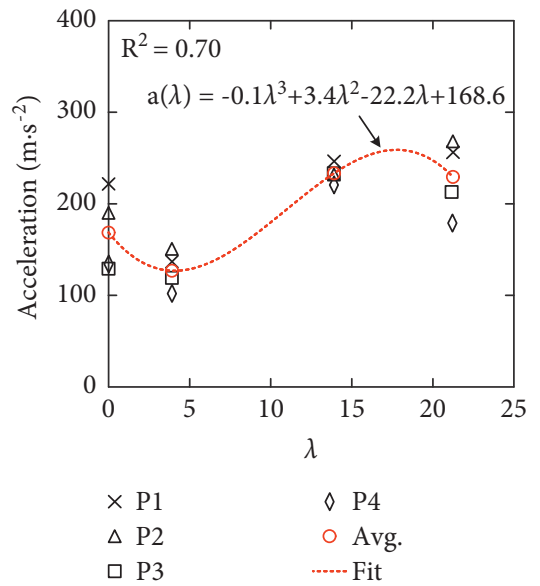

(a)

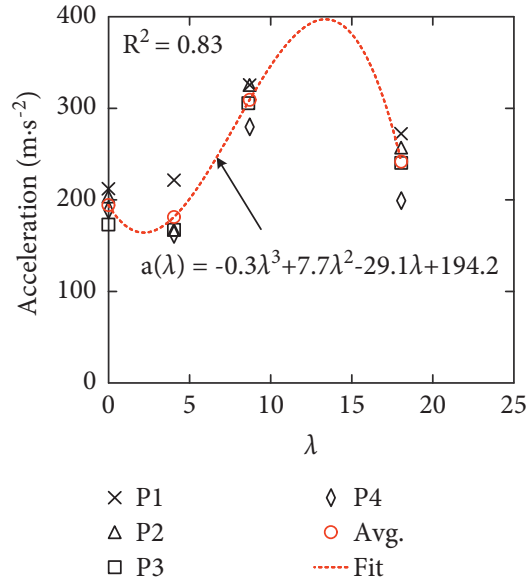

(b)

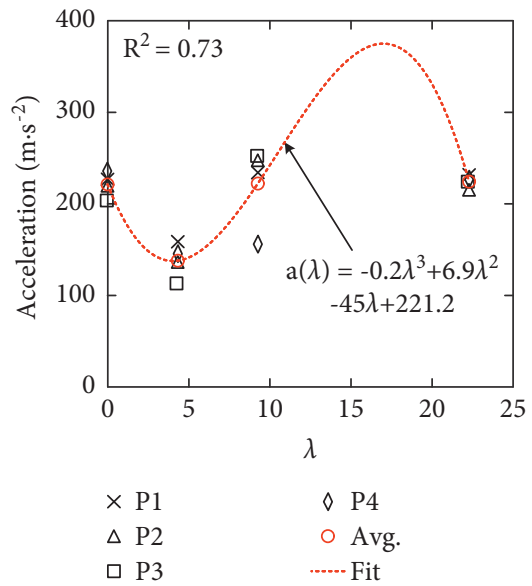

(c)

FIgURE 7: The relationship between the acceleration of the sensor and $\lambda$ in (a) tree I, (b) tree II, and (c) tree III.

for a polynomial model should be equal to the number of data points minus one. In the case of this study, since the number of data points was four, the changes in acceleration as a function of $\lambda$ can be mathematically modeled with a third-degree polynomial function:

$$
a(\lambda)=\sum_{k=0}^{3} c_{k} \lambda^{k},
$$

where $c_{k}$ is the coefficient of the function and its values are changed depending on the morphology of the tree. The coefficient of determination of the goodness of fit $R^{2}$ for equation (8) was calculated using

$$
R^{2}=1-\frac{\mathrm{RSS}}{\mathrm{TSS}}
$$

where RSS is the sum of squares of residuals, and TSS is the total sum of squares [25].

Overall, based on the results shown in Figure 7, the third-degree polynomial model acceptably fits the resultant acceleration peaks in different locations on the tree for different patterns. However, for the large tree, all patterns were producing large variability in data points where $\lambda$ was equal to 0 and 21.24 at the locations of the sensor installed on the machine's shaker head and the last branch. In the medium tree, the large variability in data points happened 
only for P1 at the location of the first branch where $\lambda$ was equal by 4.04 and only for P4 at the locations of the second and third branches where $\lambda$ was equal by 8.71 and 18.06 , respectively. In the small tree, the variability in data points happened only for P2 at the location of the first branch where $\lambda$ was equal by 4.32 and only for P 4 at the location of the second branch where $\lambda$ was equal by 9.24 . In general, this mathematical model can estimate the approximate acceleration at the last branch in smaller trees pricier than the larger trees.

In order to evaluate the performance of the suggested mathematical model, some random size trees were selected. These trees were shaken with different patterns which are decided based on the age of the trees and experienced by an expert shaker operator to minimize causing undesirable damage to the trees. Dimensional values of each tree, sensor location index $\lambda$, the acceleration value in each sensor location, and results of fitting for equation (8) are given in Table 1. In this table, $c_{0}, c_{1}, c_{2}$, and $c_{3}$ are the coefficients of equation (8); $R^{2}$ is the coefficient of determination for this third-degree polynomial mathematical model.

Based on the results given in Table 1, the third-order polynomial mathematical model can simply fit all acceleration data points at every sensor location index $\lambda$. It means that regardless of the shaking patterns, the distribution of transferred acceleration at different branches follows equation (8). Figure 8 shows the resulting polynomial function for each tree obtained from Table 1. As shown for large trees, equation (8) fitted very well. However, for small trees in general, $R^{2}$ of equation (8) was lower than larger trees. This reduction could be due to the increased flexibility of the branches in younger trees. In one of the young trees which is shown in Figure 8(c), this effect was more pronounced. This issue with young trees can also cause an uncertain peak of resultant acceleration in the first and second branches. As a result, this phenomenon can considerably increase the chance of getting outlier data points in these locations when younger trees are shaken.

Overall, $R^{2}$ does not represent a good shake of the tree. But, this is just showing how good data points were fitted to the suggested function of equation (8). The desirable acceleration transmission across the tree branches for an efficient harvest should be something similar to what was happened only on trees 4, 5, 6, and 7 in Figures $8(\mathrm{~d})-8(\mathrm{~g})$ when the trees were shaken with the patterns $\mathrm{P} 3$ and P4. In patterns $\mathrm{P} 3$ and $\mathrm{P} 4$, less shaking energy was applied to the trunk, while the maximum energy was transferred to the canopy level where the fruits were located. Patterns P1 and P2 applied a high amplitude of acceleration on the first and second branches of trees 5 and 6 (Figures $8(\mathrm{e})$ and $8(\mathrm{f})$ ), which could cause a branch breakage to happen. Secondary branches are the main big productive branches of the tree and should avoid damaging them during harvest.

Moreover, a new parameter $\gamma$ was defined.

$$
\gamma=\frac{\sum_{i=1}^{3} L_{i}}{D_{1}},
$$

where $L_{i}$ is the length of the tree's branches and $D_{1}$ is the diameter of the first branch of the tree that their values can be extracted from Table 1. After applying the linear regression on data points of each coefficient $c_{0}, c_{1}, c_{2}$, and $c_{3}$ of equation (8) as a function of variable $\gamma$, the result for each coefficient is shown in Figure 9.

The flexibility of the tertiary branch of the tree is proportional to the ratio of $L_{3} / D_{3}$ [26], where $L_{3}$ is the length and $D_{3}$ is the diameter of the third branch of the tree. The result of the goodness of fit $R^{2}$ of equation (8) versus the approximate ratio of $L_{3} / D_{3}$ is shown in Figure 10. As this is clear in this figure, $R^{2}$ of the fitted third-degree polynomial function of (8) is higher than 0.8 (acceptable fit) where the ratio of $L_{3} / D_{3}$ is lower than 15 , and this is below 0.8 (weak fit) where the ratio is greater than 15 .

Based on the result of this experiment, applying shaking patterns $\mathrm{P} 3$ and $\mathrm{P} 4$ obtained the best result with less damage to middle age trees $4,5,6$, and 7 . Due to the high flexibility of branches, different shaking parameters should be selected for younger trees to achieve optimal fruit removal with minimum damage to the tree. Moreover, the chance of tree damages in the trunk and first and second branches are high when they are shaken with shaking patterns similar to P1 and $\mathrm{P} 2$.

\subsection{The Changing Trend and Transmission of the Force and} Kinetic Energy. The variation and transmission of RFR can be calculated using equation (5) from the shaking point to the top branch of the tree for each sensor location index $\lambda$. The results of the relative force ratio versus $\lambda$ for the four different shaking patterns in three trees are shown in Figure 11. In general, as can be observed in this figure, RFR was decreased when $\lambda$ increased. However, the decrease rate was different for different patterns. As a result, by considering the mass of the tree, the best pattern that could transfer higher force to the last branch was P3 for all three trees. Surprisingly, it was found that it is not necessary to apply a long time shaking (Figures 2(a), 2(b), and 2(d)) to transfer a high amount of force to the last branch; a small shock (Figure 2(c)) achieves detachment of fruit without causing much damage to the bark of the tree trunk.

The variation and transmission of the RKER can be calculated using equation (6) from the shaking point to the top branch of the tree for each $\lambda$. The results of the relative kinetic energy ratio versus $\lambda$ for the four different shaking patterns in three trees are shown in Figure 12. Based on this result, it was found that the higher rate of the kinetic energy which was transferred to the last branch was pattern P2 in tree I, P1, and after that P2 in tree II, and P3 and after that P2 in tree III.

Moreover, it was found the shape and age of the tree influence the result, and these morphological matters cause more complexity to the transfer system for the kinetic energy. This complexity is shown as fluctuations in the values of RKER, which has an unknown correlation with $\lambda$. The values of RKER of tree I are less than one and much smaller than those of the other two trees. Hence, more energy is needed to harvest nuts from larger pistachio trees because the large branches can absorb more energy and cause more damping of force and kinetic energy transmission. 


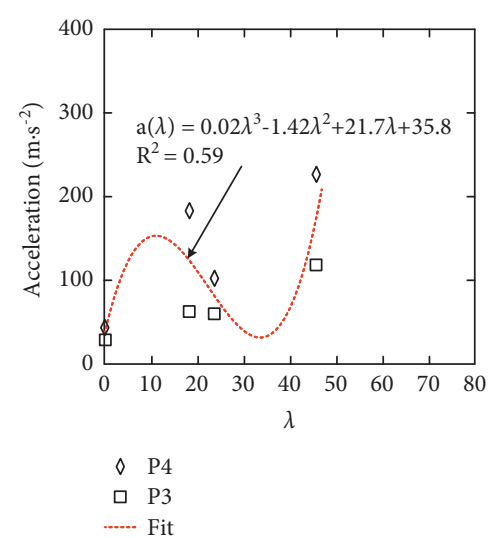

(a)

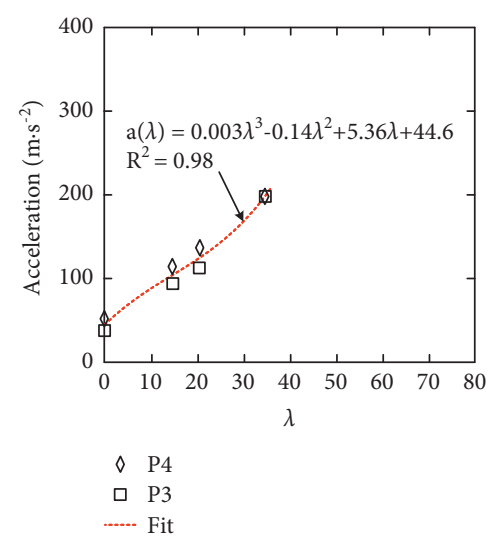

(d)

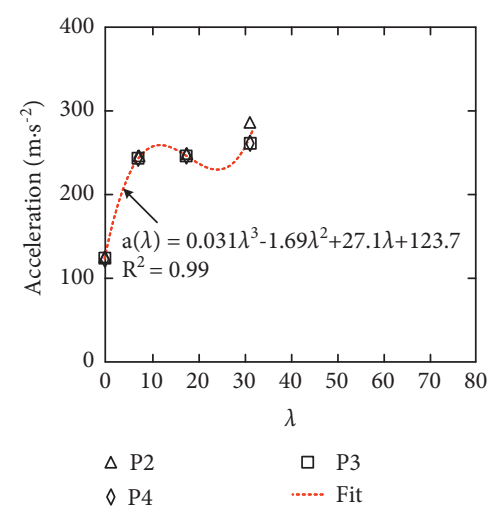

(g)

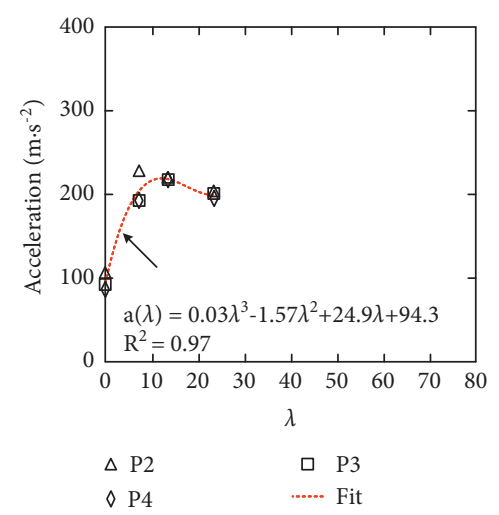

(j)

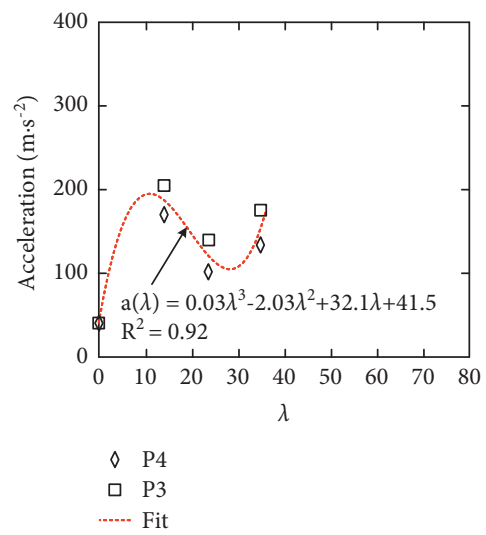

(b)

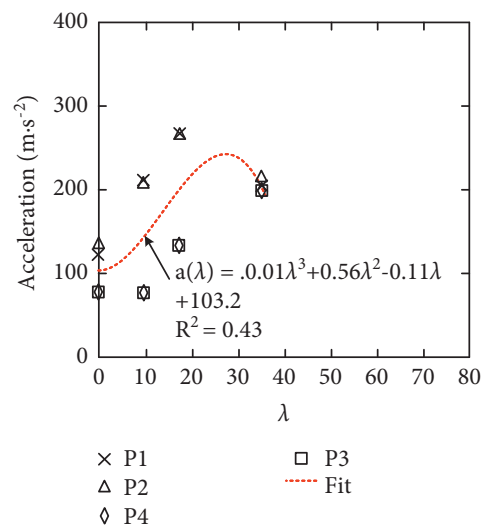

(e)

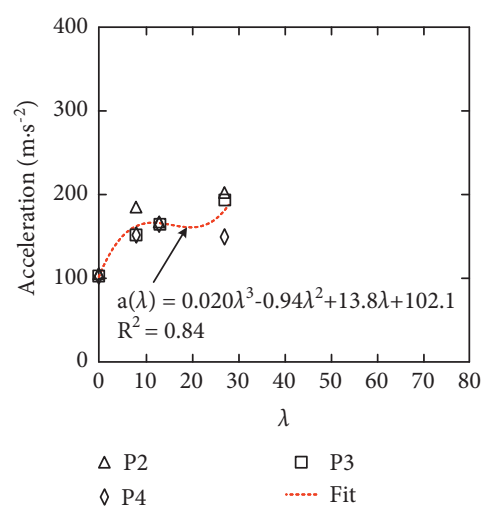

(h)

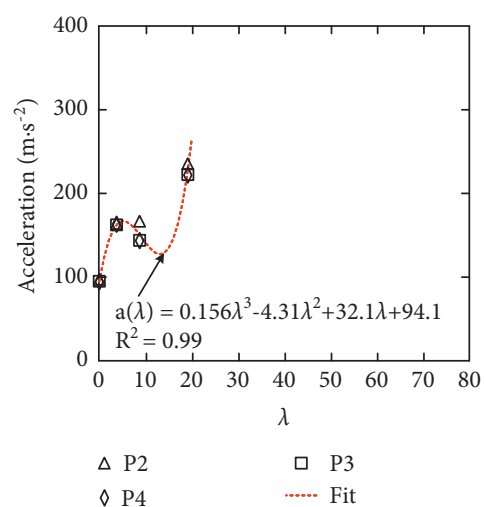

(k)

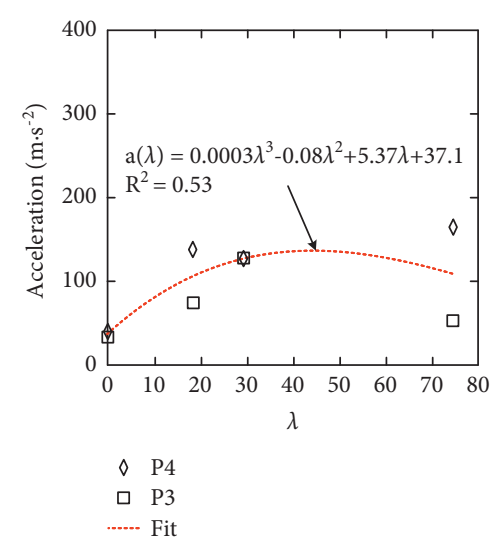

(c)

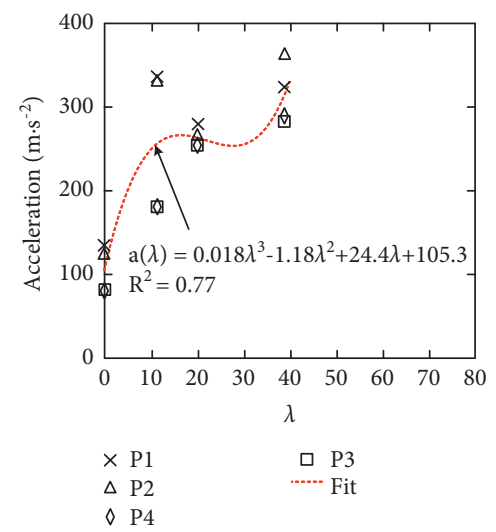

(f)

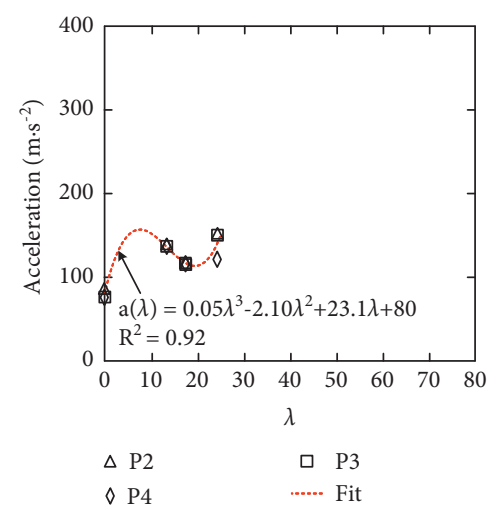

(i)

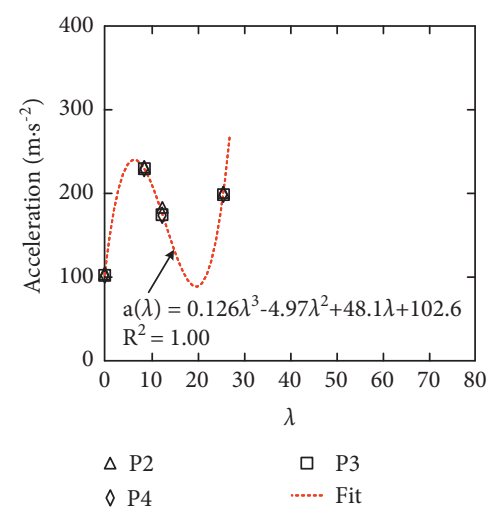

(1)

Figure 8: The relationship between the acceleration of the sensor and $\lambda$ in trees (a) 1, (b) 2, (c) 3, (d) 4, (e) 5, (f) 6, (g) 7, (h) 8, (i) 9, (j) 10, (k) 11 , and (l) 12. 


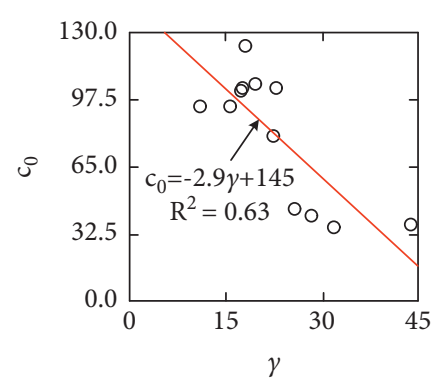

(a)

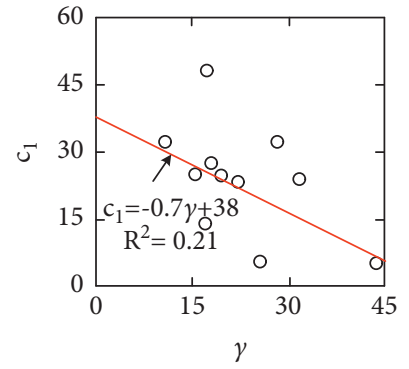

(b)

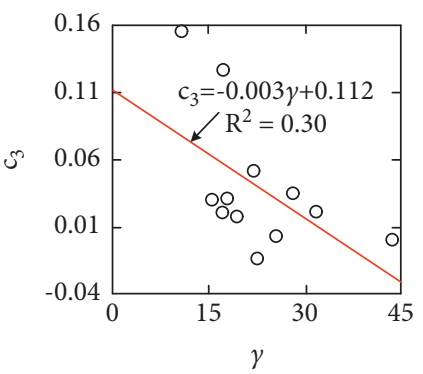

(d)

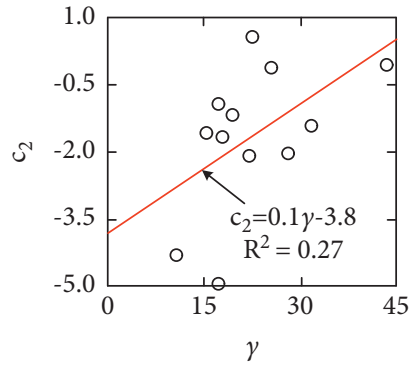

(c)

Figure 9: $\gamma$ vs. coefficients $(\mathrm{a}) c_{0}$, (b) $c_{1},(\mathrm{c}) c_{2}$, and $(\mathrm{d}) c_{3}$.

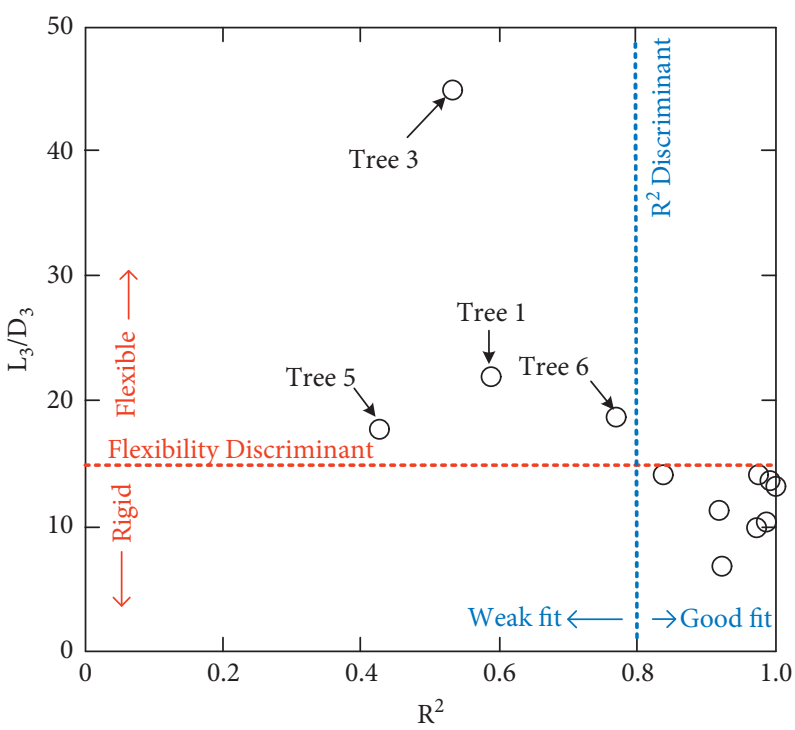

Figure 10: Goodness of fit $R^{2}$ vs. the ratio of $L_{3} / D_{3}$.

Finally, it is important to highlight that finding the optimum shaking pattern by considering the acceleration alone is not enough. It requires the study of other parameters, including tree morphology, shaking velocity, displacement, and mass. The introduced $\lambda$ can assist in clarifying and estimating how far the shaking energy can be transferred and how much the generated force was damped as a function of $\lambda$ using different shaking patterns. Both RFR and RKER in the third branch were higher where $\lambda$ is smaller. Based on equation (2), $\lambda$ is dependent on the distance of the sensor from the shaking point and diameter of the branch. Although we do not have control over the diameter size of the branch, the distance from the shaking point can be decreased by pruning the third long branch of the large trees. This can decrease the value of $\lambda$ and achieve a higher RFR and RKER at the third branch, which can raise the chance of fruit removal and reduce the tree damages by applying a less amount of force or energy to the trunk of the tree. 


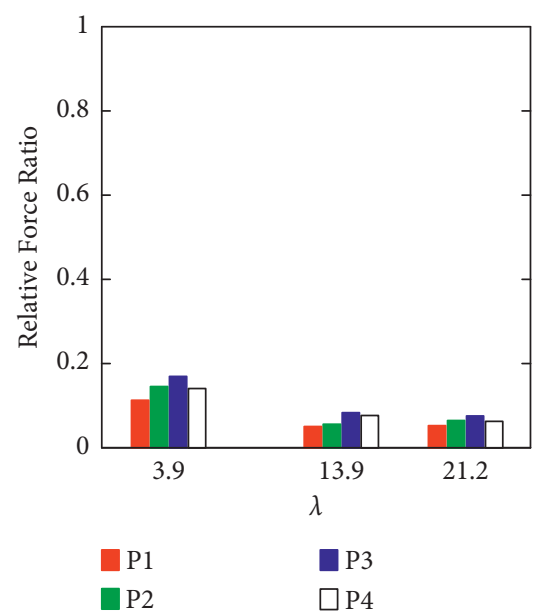

(a)

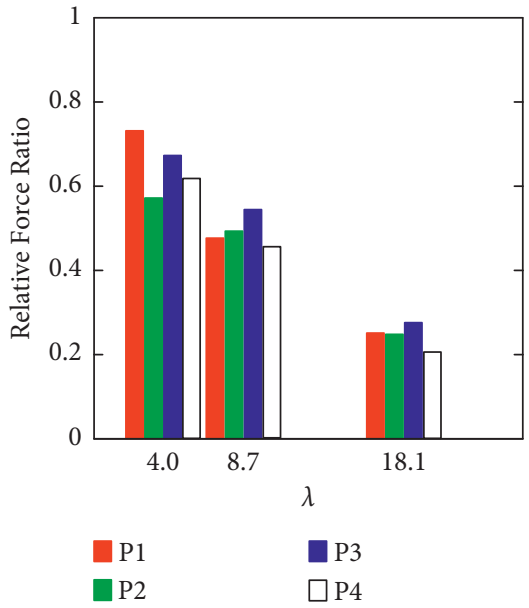

(b)

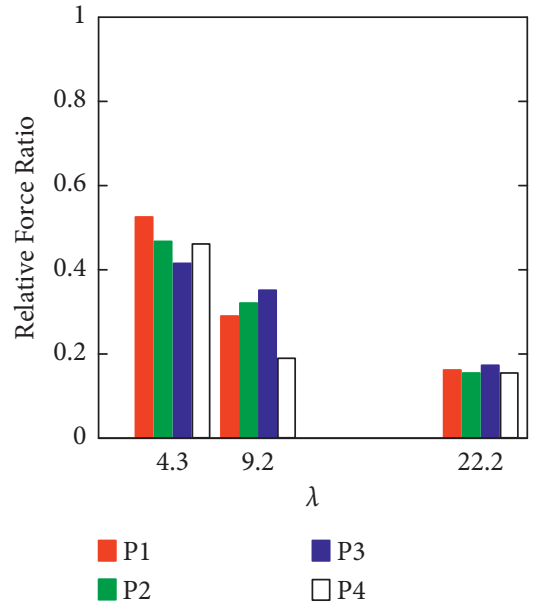

(c)

FiguRE 11: The relationship between the relative force ratio and sensor location index $(\lambda)$ for different shaking patterns in (a) tree I, (b) tree II, and (c) tree III.

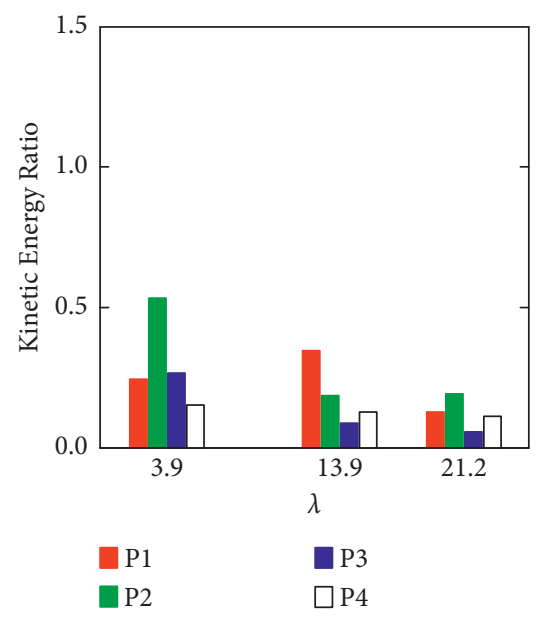

(a)

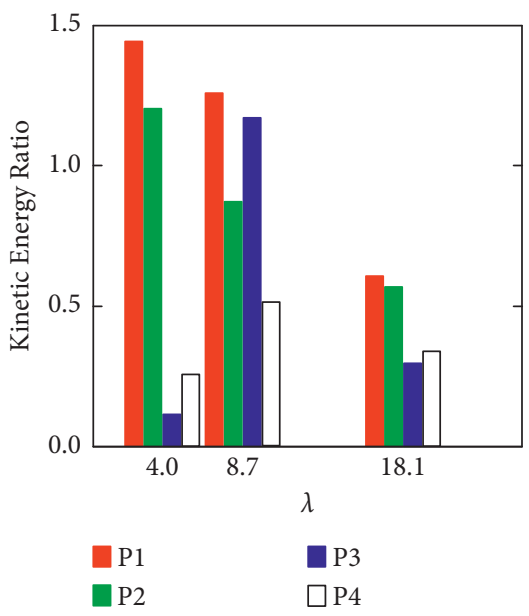

(b)

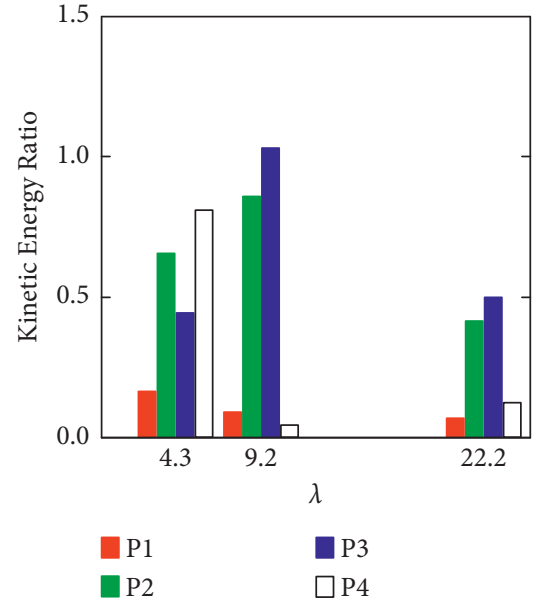

(c)

FIgURE 12: The relationship between the kinetic energy ratio and $\lambda$ for different shaking patterns in (a) tree I, (b) tree II, and (c) tree III.

\section{Conclusions}

To improve the efficiency of fruit removal and reduce damage to the tree by trunk shaking harvesting machines, it is important to quantify the amount of energy input to the trunk and amount of the kinetic energy that is transferred throughout the tree canopy to reach the fruit. It was found out that a third-degree polynomial function can be suitable for mathematical modeling of the resultant acceleration magnitude as a function of $\lambda$. Also, it was found that RFR decreases as $\lambda$ increases, and the rate of the decrease is different for different shaking patterns. The changes of RKER were hard to predict, and it may be influenced by other parameters such as the size and shape of the tree morphology and shaking patterns. However, based on the calculated results of the transmitted RFR and RKER, it can be concluded that a larger pistachio tree needs more energy to be harvested using an inertia-type trunk shaker. For large trees, most of the applied force to the trunk can be damped in the first and secondary branches, and a smaller amount of the shaking energy is transmitted to the tertiary branch. There is a limit on increasing the input force and energy to a larger tree since increased force or energy could cause structural damage to trees or damages the trees' root system. For the large trees, horticultural practices such as pruning, topping, and hedging to reduce the length of the tertiary branches could be a better option for reducing the required force for efficient harvesting using trunk shakers. Also, the results suggest that pruning the long branch can reduce damping and potentially increase fruit removal.

\section{Data Availability}

The data used to support the findings of this study are currently under embargo while the research findings are commercialized. 


\section{Conflicts of Interest}

The authors declare that they have no conflicts of interest.

\section{Acknowledgments}

This research was partially supported by the California Pistachio Research Board and the National Natural Science Foundation of China (31471418). The authors would like to acknowledge the China Scholarship Council for supporting visiting scholars who worked on this project at the University of California, Merced, during 2018-2019. They would also like to show their gratitude to the Wonderful Company LLC for allowing them to access their orchard and help them during in-field data collection.

\section{References}

[1] C. E. Kallsen, D. E. Parfitt, J. Maranto, and B. A. Holtz, "New pistachio varieties show promise for California cultivation," California Agriculture, vol. 63, no. 1, pp. 18-23, 2009.

[2] Administrative Committee for Pistachios, "2019 Pistachio Bearing Acreage, Production and Yield Per Acre by District and County," 2020, https://acpistachios.org/wp-content/ uploads/2020/02/2019-Pistachio-Statistics-Revised-1.pdf.

[3] L. Afsah-Hejri, T. Homayouni, A. Toudeshki, L. Ferguson, S. Castro-Garcia, and R. Ehsani, "Mechanical harvesting of selected temperate and tropical fruit and nut trees," Horticultural Reviews, vol. 49, no. 4, pp. 171-242, 2022.

[4] A. William, "U.S," U.S. Patent and Trademark Office, Washington, DC, USA, Patent No. 1,472,262, 1923.

[5] E. Horvath and G. Sitkei, "SE-structures and environment," Journal of Agricultural Engineering Research, vol. 80, no. 2, pp. 191-199, 2001.

[6] H. A. Affeldt Jr., G. K. Brown, and J. B. Gerrish, "A new shaker for fruit and nut trees," Journal of Agricultural Engineering Research, vol. 44, pp. 53-66, 1989.

[7] Y. Pu, A. Toudeshki, R. Ehsani, F. Yang, and J. Abdulridha, "Selection and experimental evaluation of shaking rods of canopy shaker to reduce tree damage for citrus mechanical harvesting," International Journal of Agricultural and Biological Engineering, vol. 11, no. 2, pp. 48-54, 2018.

[8] Y. Pu, A. Toudeshki, R. Ehsani, and F. Yang, "Design and evaluation of a two-section canopy shaker with variable frequency for mechanical harvesting of citrus," International Journal of Agricultural and Biological Engineering, vol. 11, no. 5, pp. 77-87, 2018.

[9] R. Polat, I. Gezer, M. Guner, E. Dursun, D. Erdogan, and H. C. Bilim, "Mechanical harvesting of pistachio nuts," Journal of Food Engineering, vol. 79, no. 4, pp. 1131-1135, 2007.

[10] Z. Láng, "Dynamic modelling structure of a fruit tree for inertial shaker system design," Biosystems Engineering, vol. 93, no. 1, pp. 35-44, 2006.

[11] H. Hoshyarmanesh, H. R. Dastgerdi, M. Ghodsi, R. Khandan, and K. Zareinia, "Numerical and experimental vibration analysis of olive tree for optimal mechanized harvesting efficiency and productivity," Computers and Electronics in Agriculture, vol. 132, pp. 34-48, 2017.

[12] S. K. Gupta, R. Ehsani, and N. H. Kim, "Optimization of a citrus canopy shaker harvesting system: properties and modeling of tree limbs," Transactions of the ASABE, vol. 58, no. 4, pp. 971-985, 2015.
[13] T.-H. Liu, G. Luo, R. Ehsani, A. Toudeshki, X.-J. Zou, and H.-J. Wang, "Simulation study on the effects of tine-shaking frequency and penetrating depth on fruit detachment for citrus canopy-shaker harvesting," Computers and Electronics in Agriculture, vol. 148, pp. 54-62, 2018.

[14] H. M. Abdel-Fattah, K. A. Shackel, and D. C. Slaughter, "Methodology for determining almond shaker displacement and frequency," Applied Engineering in Agriculture, vol. 19, no. 2, p. 141, 2003.

[15] P. Amirante, P. Catalano, F. Giametta, A. Leone, and G. L. Montel, "Vibration analysis of an olives mechanical harvesting system," Agricultural Engineering International: CIGR Journal, vol. IX, pp. 1-10, 2007.

[16] P. Catania, F. Bono, and M. Vallone, "Evaluation of the vibrations transmitted to the hand-arm system in the use of portable harvesters for olives," Agricultural Engineering International: CIGR Journal, vol. 19, no. 2, pp. 129-138, 2017.

[17] S. Castro-Garcia, R. R. Sola-Guirado, and J. A. Gil-Ribes, "Vibration analysis of the fruit detachment process in lateseason 'Valencia' orange with canopy shaker technology," Biosystems Engineering, vol. 170, pp. 130-137, 2018.

[18] S. Castro-Garcia, F. J. Castillo-Ruiz, F. Jimenez-Jimenez, J. A. Gil-Ribes, and G. L. Blanco-Roldan, "Suitability of Spanish 'Manzanilla' table olive orchards for trunk shaker harvesting," Biosystems Engineering, vol. 129, pp. 388-395, 2015.

[19] T. H. Liu, R. Ehsani, A. Toudeshki, X. J. Zou, and H. J. Wang, "Experimental study of vibrational acceleration spread and comparison using three citrus canopy shaker shaking tines," Shock and Vibration, vol. 2017, Article ID 9827926, 9 pages, 2017.

[20] T.-H. Liu, R. Ehsani, A. Toudeshki, M. Abbas, and X.-J. Zou, "Shaking functionality evaluation of four different types of citrus canopy-shaker tines," Applied Engineering in Agriculture, vol. 34, no. 5, pp. 809-817, 2018.

[21] L. He, H. Fu, M. Karkee, and Q. Zhang, "Effect of fruit location on apple detachment with mechanical shaking," Biosystems Engineering, vol. 157, pp. 63-71, 2017.

[22] L. He, J. Zhou, X. Du, D. Chen, Q. Zhang, and M. Karkee, "Energy efficacy analysis of a mechanical shaker in sweet cherry harvesting," Biosystems Engineering, vol. 116, no. 4, pp. 309-315, 2013.

[23] X. Du, D. Chen, Q. Zhang, P. A. Scharf, and M. D. Whiting, "Dynamic responses of sweet cherry trees under vibratory excitations," Biosystems Engineering, vol. 111, no. 3, pp. 305-314, 2012.

[24] F. Pezzi and C. Caprara, "Mechanical grape harvesting: investigation of the transmission of vibrations," Biosystems Engineering, vol. 103, no. 3, pp. 281-286, 2009.

[25] J. Miles, "R-squared, adjusted R-squared," Encyclopedia of Statistics in Behavioral Science, vol. 4, pp. 1655-1657, 2005.

[26] H. N. W. Lekkerkerker and A. Stroobants, "Phase behaviour of rod-like colloid+flexible polymer mixtures," Il Nuovo Cimento - B D, vol. 16, no. 8, pp. 949-962, 1994. 